\title{
Análise das práticas de governança corporativa e sua relação com o compartilhamento do conhecimento em instituições do terceiro setor
}

\author{
Analysis of corporate governance practices and their relationship with knowledge sharing in \\ third sector institutions
}

Luis Fernando Conduta
Doutorando em Ciência da Informação pela Universidade Estadual Paulista "Julio de Mesquita Filho" - UNESP,
campus de Marília, Brasil.
Professor Assistente na Universidade Positivo.
E-mail: fernando.condutta@gmail.com

Marcia Cristina de Carvalho Pazin Vitoriano

Doutorado em História Social pela Universidade de São Paulo - USP, Brasil. Docente do Departamento de Ciência da Informação, da Faculdade de Filosofia e Ciências da Universidade Estadual Paulista "Julio de Mesquita Filho" - UNESP, campus de Marília, Brasil.

E-mail: $\underline{\text { marcia.pazin@ unesp.br }}$

\begin{abstract}
Resumo
As mudanças ocorridas no cenário empresarial brasileiro, com a ampliação da complexidade de sua atuação e surgimento de novos atores no ambiente organizacional têm influenciado diretamente as organizações do Terceiro Setor, representadas por fundações e associações que, assim como as empresas, necessitam de boas práticas de governança, o que inclui o compartilhamento de conhecimento. Em função desse contexto surge o problema de pesquisa que se traduz nas seguintes questões: as entidades do terceiro setor atendem as exigências trazidas pela prática de Governança Corporativa? Elas apresentam em sua estrutura os pilares de Gestão do Conhecimento e esses promovem o compartilhamento de conhecimento nessas instituições? Considerando essas questões o presente estudo teve como objetivo geral analisar as atividades das Associações Assistenciais, buscando compreender se essas instituições possuem os pilares necessários para a aplicação das práticas de Governança Corporativa bem como se essas práticas promoverão o compartilhamento do conhecimento nessas instituições. A metodologia caracteriza-se como qualitativa, de natureza exploratória e descritiva. Como método de pesquisa foi utilizado o estudo de caso múltiplo, tendo como universo de pesquisa um conjunto de associações de cunho assistencial localizadas no munícipio de Curitiba-PR. Os resultados obtidos demonstram que as Associações estudadas compreendem a importância das boas práticas de Governança Corporativa e seguem alguns de seus princípios, atendendo parcialmente aos pilares, de forma intrínseca ou não; têm ciência da aplicação ou aplicamnos mesmo sem os conhecer, respectivamente. Pode-se concluir que as organizações estudadas atendem parcialmente, às exigências expostas pela Governança Corporativa, mesmo que muitas vezes o façam de maneira instintiva.
\end{abstract}

Palavras-chave: Governança Corporativa, Gestão do Conhecimento, Compartilhamento de Conhecimento, Demonstrações Contábeis.

\begin{abstract}
The changes that have occurred in the Brazilian business scenario, with the expansion of the complexity of its performance and the emergence of new actors in the organizational environment, have directly influenced Third Sector organizations, represented by foundations and associations, which, like companies, need good governance practices, which includes knowledge sharing. In this context, the research problem arises, which translates into the following questions: do assistance associations meet the requirements brought about by Corporate Governance Do they have the Knowledge Management pillars in their structure and do they promote knowledge sharing in these institutions? Considering these issues, the present study had the general objective of analyzing the activities of Assistance Associations, seeking to understand whether these institutions have the necessary pillars for applying Corporate Governance as well as whether these practices will promote the knowledge sharing in these institutions. The methodology is characterized as qualitative, exploratory and descriptive. As a research method, the multiple case study was used, having as a universe of research a set of assistance associations located in the municipality of Curitiba-PR. Results demonstrate that studied Associations understand the importance of good Corporate Governance practices and follow some of its principles, partially attending to the pillars, intrinsically or not; they are aware of the application or apply it without even knowing it, respectively. It can be concluded that the organizations studied partially meet the requirements exposed by Corporate Governance, even though they often do so instinctively.
\end{abstract}

Keywords: Corporate Governance; Knowledge Management; Knowledge sharing; Accounting statements.

InCID: R. Ci. Inf. e Doc., Ribeirão Preto, v. 11, n. 2, p. 37-59, set. 2020/fev. 2021.

DOI: 10.11606/issn.2178-2075.v11i2p37-59 


\section{Introdução}

O cenário empresarial brasileiro está em um momento de transição, e essa mudança tem promovido uma mudança na perspectiva da gestão organizacional, fazendo com que os investidores institucionais se tornem mais presentes nas tomadas de decisões, no fracionamento do controle acionário e, também, no atendimento cada vez maior às regras de conformidade contábil e financeira (compliance) e à transparência dos atos da gestão. À medida que as organizações crescem, seus processos e fluxos de informações vão ficando cada vez mais complexos. Esta complexidade tem se expandido com as transformações dos mercados, cada vez mais globalizado e com menores falhas, com o avanço da tecnologia e a instabilidade econômica e ampliado a busca por equilíbrio entre os diversos atores sociais representativos para a organização (shareholders e stakeholders ${ }^{l}$ ).

Neste contexto, o Terceiro Setor ganha destaque, visto que, ao longo do tempo, passou a desempenhar um papel social muito importante, e devido a sua expansão, começou a demonstrar tanto necessidades específicas, quanto suas limitações, que são diferentes dos setores tradicionais. O Terceiro Setor é formado por um "conjunto de organismos, organizações ou instituições dotadas de autonomia e administração própria que apresentam como função e objetivo principal atuar voluntariamente junto à sociedade civil visando ao seu aperfeiçoamento (BARBIERI, 2008, p. 57). Configuram-se como entidades sem fins lucrativos, principalmente fundações e associações, com fins públicos e sociais.

O tema da Governança Corporativa, oriundo do ambiente empresarial, ganha novo significado quando abordado dentro do Terceiro Setor. A adoção das boas práticas de monitoramento e acompanhamento pela direção superior, que caracteriza a Governança Corporativa, faz com que as organizações da sociedade civil possam ter um avanço no seu processo de gerenciamento administrativo e financeiro, além de agregar credibilidade e confiabilidade, tanto à imagem organizacional quanto às informações apresentadas, ampliando a respeitabilidade do setor como um todo.

\footnotetext{
${ }^{1}$ Shareholders é o termo em inglês utilizado para definir os acionistas, pessoas físicas ou jurídicas proprietárias de ações de uma sociedade anônima. Por analogia, a área de Administração de Empresas utiliza a terminologia para definir todos os acionistas, sócios e proprietários de uma organização.

Stakeholders e o termo em inglês utilizado para definir todos aqueles grupos de interesse, contemplando acionistas, funcionários, fornecedores, consumidores e também a comunidade da região em que se localiza, que influenciam a gestão de uma entidade ou empresa e que devem ser consideradas como elementos essenciais no planejamento estratégico da organização, estabelecendo uma rede de relacionamento com a organização. (SZABO; COSTA; RIBEIRO, 2014)
}

InCID: R. Ci. Inf. e Doc., Ribeirão Preto, v. 11, n. 2, p. 37-59, set. 2020/fev. 2021. 
Da mesma forma que os escândalos financeiros, devido a fraudes e desvios de dinheiro, atingiram uma série de empresas no Brasil nos últimos anos, e a consequente crise de credibilidade que atinge a economia do país, deixando investidores receosos sobre a aplicação de recursos (MARTINS; VENTURA, 2020), essa crise de credibilidade também atinge as entidades do Terceiro Setor, principalmente por ser esse um setor ainda jovem no Brasil, com muitas entidades carentes de práticas de gestão consolidadas e confiáveis. Entende-se que a Governança Corporativa contempla um conjunto de ferramentas que podem ajudar as organizações a terem mais fidedignidade nas Demonstrações Financeiras e em seus processos. Ao aplicar as práticas de Governança Corporativa, todos os interessados (stakeholders) passam a ter uma visão mais positiva sobre as entidades, ajudando-as a angariar mais recursos, bem como a melhorar as condições de financiamentos para financiar suas operações. Destaca-se que a ausência na aplicação dos pilares tende a ocasiona a perda de oportunidades para angariar recursos, uma vez eu muitos possíveis contribuidores preferem colaborar com organizações mais confiáveis, dentre as muitas entidades do Terceiro Setor hoje existentes.

Segundo o Ministério de Justiça (2020) há 6.218 entidades do Terceiro Setor no Brasil, incluindo Associações, Fundações e demais organizações da sociedade civil como aquelas qualificadas como Organização da Sociedade Civil de Interesse Público (OSCIP), dentre outras, sendo distribuídas pelos 26 Estados e o Distrito Federal (DF) do Brasil.

Considerando as diferenças regionais e as mudanças ocasionadas no contexto do Terceiro Setor ao longo dos últimos anos, pela adoção de boas práticas de Governança Corporativa por parte das entidades, entende-se ser representativa a sua relação com o compartilhamento do conhecimento e, nessa linha, apresenta-se a hipótese de que, quando há uma adoção das boas práticas de GC em instituições do TS, então, há incentivo no processo de compartilhamento do conhecimento nessas instituições.Com a finalidade de identificar se os pilares da Governança Corporativa estão sendo praticados por entidades do Terceiro Setor com ênfase assistencial no Município de Curitiba e se estão aptas para atender os pilares da Governança Corporativa, assim como esse processo pode contribuir no compartilhamento do conhecimento nessas instituições, apresenta-se os seguintes problemas de pesquisa: As entidades do Terceiro Setor têm atendido as exigências trazidas pela prática da Governança Corporativa? E, ainda, elas apresentam em sua estrutura os pilares de GC e colaboram para o compartilhamento do conhecimento nessas instituições? 
Para responder a estas questões, a presente pesquisa tem como objetivo geral analisar as atividades de entidades do Terceiro Setor, buscando compreender se essas instituições possuem os pilares necessários para a aplicação das práticas de Governança Corporativa, bem como se essas práticas promovem o compartilhamento do conhecimento nessas instituições. Os objetivos específicos são: (a) identificar quais são os pilares fundamentais da Governança Corporativa para as entidades do Terceiro Setor; (b) verificar se as entidades estudadas praticam ou se a sua administração tem plano formalizado para implementar práticas de GC no médio prazo; e (c) apresentar como os pilares de Governança Corporativa poderão promover o ajustamento do processo de compartilhamento do conhecimento nas entidades estudadas.

Para realização da pesquisa, de natureza qualitativa e caráter exploratório e descritivo, foi realizado um estudo de caso múltiplo, em entidades do Terceiro Setor localizadas em Curitiba/PR. Entende-se que este estudo poderá servir de base para que as entidades do Terceiro Setor compreendam um pouco mais sobre Governança Corporativa, bem como os benefícios de sua aplicação, que podem contribuir para a melhoria no compartilhamento do conhecimento.

\section{Governança Corporativa}

Governança Corporativa ou Corporate Governance é um conjunto de regras, práticas e processos que possuiu como finalidade melhorar o desempenho de uma entidade protegendo todos grupos de interesses envolvidos no processo (stakeholders) (SILVA, 2016). A Governança Corporativa, também, fornece a estrutura para a empresa alcançar os seus objetivos, pois envolve praticamente todas as esferas da administração, desde os planos de ações e controles internos até a mensuração do desempenho e divulgação corporativa.

O referencial teórico da presente pesquisa está baseado na caracterização da Governança Corporativa, na análise das condições de seu desenvolvimento no Brasil e na apresentação dos pilares e princípios básicos para sua aplicação. 


\subsection{Características fundamentais da governança corporativa}

A Governança Corporativa está relacionada aos processos, políticas, leis, costumes e órgãos que são utilizados para realizar ou preparar a administração de uma organização, englobando, também, as relações entre os envolvidos no processo e seus objetivos.

Busca envolver e harmonizar os interesses dos diversos atores de uma organização, como acionistas, administradores, clientes, fornecedores, financiadores, governo e comunidade.

Embora existam inúmeras definições para Governança Corporativa, percebe-se que todas possuem coesão, ou seja, ligação harmônica, em seus princípios, conceitos, práticas, finalidades e modelos, conforme as diversas conceituações:

- Sistema de Relações - Instituto Brasileiro Governança Corporativa (IBGC): Governança Corporativa é o sistema pelo qual as empresas e demais organizações são dirigidas, monitoradas e incentivadas, envolvendo os relacionamentos entre sócios, conselho de administração, diretoria, órgãos de fiscalização e controle e demais partes interessadas. As boas práticas de Governança Corporativa convertem princípios básicos em recomendações objetivas, alinhando interesses com a finalidade de preservar e otimizar o valor econômico de longo prazo da organização, facilitando seu acesso a recursos e contribuindo para a qualidade da gestão da organização, sua longevidade e o bem comum (IBGC, 2015, p. 20).

- Guardião de Direitos - Organização para a Cooperação e Desenvolvimento Econômico (OCDE): A estrutura da Governança Corporativa especifica a distribuição dos direitos e responsabilidades entre os diferentes participantes da corporação, tais como o conselho de administração, os diretores executivos, os acionistas e outros interessados, além de definir as regras e procedimentos para a tomada de decisão em relação a questões corporativas. E oferece também bases através das quais os objetivos da empresa são estabelecidos, definindo os meios para se alcançarem tais objetivos e os instrumentos para se acompanhar o desempenho (OCDE, 1999 apud ANDRADE; ROSSETTI, 2006, p. 138).

- Estrutura de Poder-Cadbury: A Governança Corporativa é o sistema e a estrutura de poder que regem os mecanismos através dos quais as entidades são dirigidas e controladas (CADBURY COMMITTE, 1992 apud ANDRADE; ROSSETI, 2006, p. 139).

- Sistema Normativo - Claessens e Fan: A Governança Corporativa diz respeito aos padrões de comportamento que levam à eficiência, ao crescimento e ao tratamento dados aos stakeholder (acionistas e a outras partes interessadas), possuindo por base princípios definidos pela ética aplicada à gestão de negócios (CLAESSENS; FAN, 2000 apud SILVA, 2016, p. 32).

- Sistema de Valores: E por fim, o sistema de valores é aquele que promove a integração entre os quatro quadrantes apresentados anteriormente, tendo como função primordial preservar pela transparência na prestação de contas, ou seja uma prestação de contas responsável (CLAESSENS; FAN, 2000 apud SILVA, 2016, p. $32)$. 
Conforme demonstrado, em todas as definições apresentadas, aparecem quatro grupos de elementos estruturantes que contemplam a gestão integral das organizações, a Governança Corporativa cria um sistema que funciona como guardião de direitos das partes com interesses em jogo. Também estabelece um sistema de relações pelo qual as organizações, empresas e demais entidades são dirigidas e monitoradas (ANDRADE; ROSSETI, 2006).

A Governança Corporativa é um assunto que possui características variadas e peculiares, especialmente por sua natureza e extensão das responsabilidades de alguns indivíduos estratégicos nas organizações. Originalmente, um dos impactos de um sistema de GC está localizado na eficiência econômica com forte destaque no bem-estar dos principais interessados, os acionistas. Quando aplicada ao Terceiro Setor, este bem-estar será redirecionado àqueles agentes sociais beneficiados pelas ações da entidade específica. São associados.

\subsection{Princípios básicos e pilares da Governança Corporativa}

São quatro os princípios básicos da Governança Corporativa: transparência, equidade, prestação de contas e responsabilidade, assim definidos pelo Instituto Brasileiro de Governança Corporativa (IBGC).

Figura 1 - Princípios básicos e pilares da Governança Corporativa

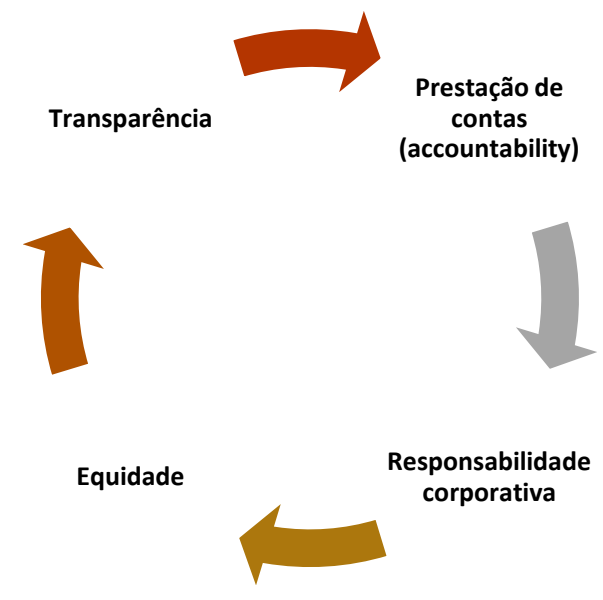

Fonte: Elaborado pelos autores (2020)

Embora tenham sido definidos para o ambiente empresarial, os princípios básicos da Governança corporativa são plenamente aplicáveis às organizações do Terceiro Setor, principalmente quando se pretende a modernização administrativa e gerencial dessas entidades. 
O princípio da transparência, fornece segurança ao doador, ou investidor social, de que a atuação da organização é demonstrável mediante o fornecimento de informações claras e objetivas, e que sua atuação pode ser comprovada mediante o acompanhamento constante de suas ações. O princípio da equidade é, em muitos casos, um dos princípios do próprio Terceiro Setor, enquanto agente social. Igualdade de tratamento, de oportunidades, de atuação são questões aplicáveis a todas as organizações da sociedade civil. A prestação de contas é um princípio que pode ser tratado como derivado da transparência. A administração financeira de uma organização sem fins lucrativos, em que os resultados devem ser reinvestidos na própria entidade, ganha contornos de obrigação moral, considerando o investimento realizado por participantes da organização em benefício de uma comunidade. Por fim, a responsabilidade corporativa está relacionada aos anteriores quando pretende garantir a sustentabilidade da organização, em caráter abrangente considerando, além da sustentabilidade financeira, também o compromisso da organização com o meio social e ambiental que a cerca, o que está em pleno acordo com as finalidades do Terceiro Setor.

Porém, é importante salientar que a transposição dos conceitos para aplicação em diferentes setores deve contemplar as diferenças existentes e suas especificidades, evitando a transposição simples de conceitos aplicáveis ao ambiente empresarial, onde o objetivo é a geração de lucro, para o ambiente social, seja ele o poder público ou o terceiro Setor, cujo objetivo é o atendimento às necessidades da sociedade. No caso da Governança, porém, há uma grande aproximação entre os princípios e pilares (BENEDICTO et al., 2013)

Ao lado dos princípios, os teóricos da Governança Corporativa defendem que ela se sustenta sobre um conjunto de itens, denominados pilares, que garantem a consecução dos princípios, por meio de operacionalização das ações necessárias principalmente à transparência, à prestação de contas e à responsabilidade corporativa. De acordo com o IBGC (2015), os seis pilares da Governança Corporativa são: 
Imagem 1 - Pilares da Governança Corporativa

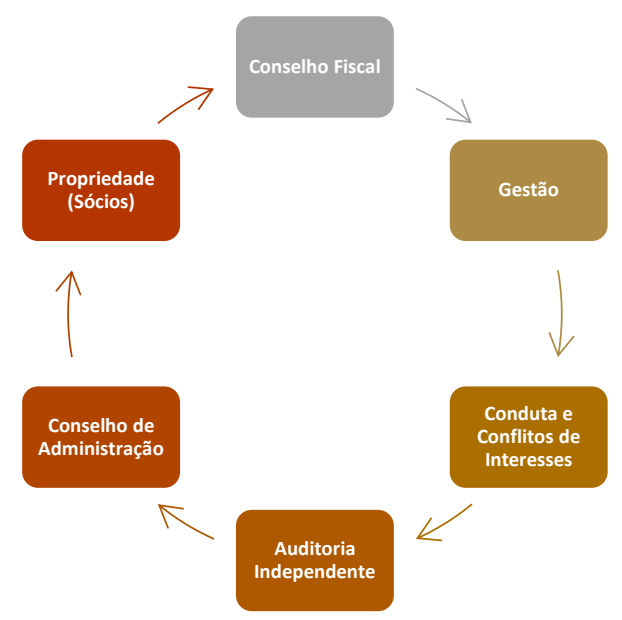

Fonte: Elaborado pelos autores (2020)

O Código IBGC (2015) discorre que além dos conselheiros, os executivos necessitam ser leais, não somente com sócios que os indicaram ou elegeram, mas também com a empresa. O conflito de interesse se instala quando alguém não é independente em relação à matéria que está sendo debatida, e pode influenciar ou tomar decisões motivadas por interesses distintos daqueles da organização.

Um dos aspectos relevantes da Governança Corporativa é que ela abarca uma nova concepção para o compartilhamento de informações e do conhecimento produzidos no ambiente das organizações. Nesta pesquisa o enfoque recai sobre a Gestão do Conhecimento e as ferramentas de que dispõe para essa tarefa.

\section{Gestão do Conhecimento}

Hoffman (2009) defende que o conhecimento é a informação valiosa contida na mente. À medida em que é explorado, o conhecimento cresce, sendo um recurso renovável, além de ser um processo dinâmico, que acompanha o desenvolvimento humano. É multidimensional e complexo, sendo apresentado em muitos contextos diferentes, numa dinâmica própria característica da mente humana.

Contempla um conjunto de elementos componentes relacionados às experiências, aos valores, às crenças, às normas, às habilidades, às ações, à inovação, aos insights provenientes do intelecto humano, que proporcionam novas experiências e informações (DAVENPORT; PRUZAK, 1998; HOFFMAN, 2009). Sendo resultado das interações humanas, é natural que o conhecimento incorpore a complexidade dos seres humanos. Por isso, para Nonaka e Takeushi 
(2008, p. 19), "as contradições, as inconsistências, os dilemas, as dualidades, as polaridades, as dicotomias e as oposições não são alheios ao conhecimento".

O conhecimento é produzido e reproduzido em dois níveis; num nível formal, registrado, representado pelo conhecimento explícito, e no nível pessoal, individual, representado pelo conhecimento tácito (NONAKA; TAKEUCHI, 2008).

Os autores explicam que:

O conhecimento explícito pode ser expresso em palavras, números ou sons, e compartilhado na forma de dados, fórmulas científicas, recursos visuais, fitas de áudio, especificações de produtos ou manuais. O conhecimento explícito pode ser rapidamente transmitido aos indivíduos, formal e sistematicamente.

O conhecimento tácito, por outro lado, não é facilmente visível e explicável. Pelo contrário, é altamente pessoal e difícil de formalizar, tornando-se de comunicação e compartilhamento dificultoso. As intuições e os palpites subjetivos estão sob a rubrica do conhecimento tácito. O conhecimento tácito está profundamente enraizado nas ações e na experiência corporal do indivíduo, assim como nos ideais, valores ou emoções que ele incorpora. (NONAKA; TAKEUCHI (2008, p. 19)

Partindo da análise dos autores, pode-se dizer que o conhecimento explícito pode ser transmitido por meio da linguagem formal dos indivíduos, enquanto o conhecimento tácito, objeto deste estudo, é transmitido pincipalmente por meio da convivência (HOFFMAN, 2016). Dada sua importância, entende-se que a articulação entre conhecimento tácito e conhecimento explícito pode ser objeto de gestão.

A Gestão do Conhecimento tem natureza multidisciplinar, sendo um conjunto de atividades que visam trabalhar a cultura e a comunicação organizacional e informacional em ambientes organizacionais (VALENTIM, 2013). Esse processo organizacional é focado na estratégia organizacional como um diferencial competitivo, no intuito de propiciar um ambiente positivo em relação à criação / geração, aquisição / apreensão, compartilhamento / socialização e uso / utilização do conhecimento (VALENTIM, 2013; HOFFMAN, 2018).

Para Valentim (2013), o objetivo da Gestão do Conhecimento é mapear os fluxos informais existentes no ambiente organizacional, para formalizá-los na medida do possível, como maneira de transformar o conhecimento tácito em explícito, fomentando o compartilhamento do conhecimento, geração de ideias, solução de problemas e o processo decisório. Para cumprir este objetivo, a criação de práticas que impulsionam o compartilhamento de conhecimento entre indivíduos, torna-se indispensável no ambiente organizacional, para que o conhecimento seja da organização e não apenas do indivíduo. 
No processo de criação do conhecimento formulado por Nonaka e Takeuchi (2008) no diagrama que apresenta a espiral do conhecimento, as fases de socialização e externalização do conhecimento demonstram a necessidade de que se estabeleçam condições para o compartilhamento do conhecimento para que seja possível a posterior combinação e internalização que resultam na efetiva criação de conhecimento. Disso se depreende que as etapas que levam ao compartilhamento de conhecimento são essenciais para que cada indivíduo tenha acesso a conhecimentos produzidos ou acumulados por outros, que ao compartilhar, colaboram para que mais um ciclo da espiral se concretize.

\subsection{Compartilhamento do conhecimento}

Se os indivíduos criam o conhecimento, então uma organização não pode criar conhecimento sozinha, sem os indivíduos (NONAKA; TAKEUCHI, 2008). Por isso, a criação do conhecimento organizacional deve ser estimulada, apoiada, encorajando as atividades criadoras de conhecimento.

Para haver a criação do conhecimento pela organização (e não apenas dos indivíduos que trabalham nela), o processo deve ser reconhecido como amplificador do conhecimento individual, que deve ser cristalizado por meio do conhecimento de grupo utilizando-se o diálogo, as discussões, o compartilhamento de experiência, ou seja, algo que tenha um objetivo e um porquê previamente estabelecido (NONAKA; TAKEUCHI, 2008).

Pode-se dizer que ainda não existe consenso sobre o que é e como ocorre o compartilhamento de conhecimento entre os indivíduos (TONET; PAZ, 2006). Bartol e Srivastava (2002, apud TONET; PAZ, 2006 definem compartilhamento de conhecimento como sendo o comportamento fomento à troca de informações, ideias, sugestões e experiências relevantes ao ambiente organizacional, do indivíduo com outros. Por isso, o compartilhamento do conhecimento é um componente-chave dos sistemas de gestão de conhecimento.

Nos diversos modos de conversão do conhecimento tácito em explícito (e vice-versa) definidos por Nonaka e Takeuchi (2008), que definem a espiral crescente que alimenta o ciclo de alimentação de novos conhecimentos, são várias as possibilidades existentes. $\mathrm{Na}$ socialização, os conhecimentos tácitos derivam em novos conhecimentos tácitos. Ao externalizar, o conhecimento tácito torna-se explícito, na medida em que o fornecimento de informações entre os agentes de conhecimento permite sua transposição para registros formais. 
A combinação, que ocorre novamente no âmbito do indivíduo possibilita a criação de sentido para o conteúdo explorado. Por fim, a internalização completa o ciclo de criação do conhecimento, quando resulta efetivamente em um novo conhecimento, incorporado ao repertório do indivíduo. Somente quando a organização fomenta o recomeço regular do ciclo e um novo processo de socialização deste conhecimento recém-adquirido tem início pode-se dizer que há efetivamente um mecanismo de gestão de conhecimento.

Um dos elementos essenciais ao sucesso do compartilhamento do conhecimento é a linguagem. Entende-se que, para haver o conhecimento transferido, precisa existir uma linguagem comum entre os indivíduos atuantes no processo, sendo o compartilhamento dependente da capacidade de absorção do destinatário, que está ligada também à motivação deste em buscar ou aceitar novos conhecimentos (TONET; PAZ, 2006). Para Hoffman (2016, p. 35),

\begin{abstract}
As práticas mais utilizadas nas organizações para a criação do conhecimento são as condições propícias que a organização oferece, que envolvem: a intenção organizacional, a autonomia das pessoas e das suas unidades, a criatividade dos seus membros, o acesso a grandes volumes de informações, a disposição para enfrentar uma variedade de situações e a interação com o ambiente externo. Essas condições conduzem a organização a vincular conhecimentos às práticas corporativas.
\end{abstract}

A criação do conhecimento, portanto, depende de um ambiente onde a cultura organizacional seja voltada ao acesso à informação, e ao estabelecimento de relações interpessoais que fomentem o contato entre os profissionais, em condições de igualdade e autonomia. A aceitação da organização como propulsora do conhecimento, faz com que sua gestão seja facilitada, uma vez que o conhecimento é obtido por meio dos indivíduos, da estrutura e dos relacionamentos estabelecidos entre os diversos elementos da organização.

No âmbito das organizações do Terceiro Setor, as inovações representadas pela adoção dos procedimentos de Governança Corporativa, baseados nos princípios de transparência, equidade, prestação de contas e sustentabilidade, podem ser amplificadas pela existência de mecanismos sistemáticos de compartilhamento do conhecimento. 


\section{Metodologia}

Para atingir o objetivo de analisar as atividades de entidades assistenciais, buscando compreender se essas instituições possuem os pilares necessários para a aplicação das práticas de Governança Corporativa, bem como se essas práticas promoverão o compartilhamento do conhecimento nessas instituições optou-se por uma abordagem de pesquisa qualitativa de caráter exploratório e descritivo, que permite aos pesquisadores destacarem elementos para diagnosticar um caso (YIN, 2015).

\subsection{Delineamento do estudo}

A pesquisa contempla um estudo caso múltiplo, tendo como universo de estudo três associações de cunho assistencial localizadas no munícipio de Curitiba-PR, apresentadas no Quadro 1. A escolha das associações estudadas ocorreu devido a sua importância para a sociedade tanto regional, quanto nacional, pois tais associações promovem uma série de atividades sociais e acabam atingindo uma parcela da população que o Estado não consegue atender. Como essas associações atendem a uma região carente do município, sofrem uma série de dificuldades e desafios para a realização de sua gestão, acredita-se que este caso atenda as expectativas em relação as informações que pode oferecer a pesquisa (FLYVBJERG, 2006).

O estudo de casos múltiplos possibilita a investigação de um fenômeno contemporâneo dentro de seu contexto, especialmente porque os limites entre o fenômeno e o contexto não estão claramente definidos (YIN, 2015).

Para diminuir os vieses de pesquisa foram utilizados diferentes tipos de fontes de informação. Os procedimentos de pesquisa envolveram a realização de três entrevistas com diferentes gestores, a pesquisa documental na legislação e em dados fornecidos pelas associações, e a realização de observação direta nas três associações, para a produção de anotações de campo realizadas pelo pesquisador com o objetivo de comparar as percepções (YIN, 2011).

Quanto ao tempo, este estudo de caso foi de corte transversal, ou seja, foi realizado em um período específico no tempo. Já a análise foi longitudinal pois os entrevistados refletem suas percepções de experiências passadas nas respostas que elaboram no presente. 
Após a coleta de dados optou-se pela Análise de Conteúdo como técnica para análise. A Análise de Conteúdo na perspectiva de Bardin (2011) é uma técnica que analisa a comunicação por meio de procedimentos que permitem compreender, explorar e averiguar o conteúdo de mensagens, dispostas neste estudo nas transcrições das entrevistas e observações.

As etapas para a realização da análise de conteúdo foram a partir do modelo de Bardin (2011): a pré-análise, as descrições analíticas e a interpretação investigativa dos resultados. Na pré-análise já foram procurados elementos que poderiam ajudar a responder o problema de pesquisa, bem com a formulação do roteiro de entrevista e de observação. Após esta fase foi feita a descrição analítica que consiste em "procedimentos sistemáticos e objetivos de descrição dos conteúdos" (BARDIN, 2011, p. 41). Para a realização desta etapa foi preciso transcrever as entrevistas, assim como definir as categorias de pesquisa.

As categorias de pesquisa foram selecionadas a partir frequência com que ocorreram ao longo das entrevistas. Foram selecionadas frases e expressões utilizadas pelos entrevistados que demonstraram maior relevância para o objeto de pesquisa. Estas frases e expressões compuseram a unidade de análise e foram dispostas nas categorias: 1)Benefícios da Governança Corporativa, 2) Estrutura do Conselho de Administração; 3)Apresentação de Demonstrações Contábeis, 4) Estrutura do organograma da entidade e gestores responsáveis pela tomada das principais decisões, 5) Decisões com base em Demonstrativos Contábeis, 6) Os pilares da governança corporativa e sua relação com o compartilhamento do conhecimento. Durante esta etapa, as categorias de análise sofreram alterações em virtude da análise dos dados coletados, que também foram agrupados em subcategorias. 

conhecimento em instituições do terceiro setor

\subsection{Universo de pesquisa e coleta de dados}

A coleta de dados foi realizada em três associações localizadas no munícipio de Curitiba-PR. A escolha destas associações foi subsidiada por indicações de um membro do conselho municipal de assistência social, que tem mais de 15 anos de profissão, como assistente social no Estado do Paraná.

Na sequência está apresentada uma breve descrição das três associações que foram universo desse estudo:

Quadro 1 - Descritivo das associações universo desse estudo

A associação 1 atua na área de: Assistencialismos, tendo como objetivo promover o resgate da família
e do cidadão em situação de vulnerabilidade social e de risco, e promovendo sua inclusão social, atuando há 15
anos, localizada na zona oeste de Curitiba/PR.

A associação 2 atua na área de: Assistencialismos, tendo como objetivo promover a criança e ao adolescente que estão em situação de vulnerabilidade, isso por meio de ações que contribuam para a qualidade de vida desses e de suas famílias, atuando há 28 anos, localizada na zona leste de Curitiba/PR.

A associação 3 atua na área de: Assistencialismos tendo como objetivo abrigar crianças retiradas da guarda dos pais pelo Conselho Tutelar devido a denúncias de maus tratos e violência., há 24 anos, localizada na zona leste de Curitiba/PR.

Fonte: Elaborado pelos autores (2020)

Devido à indicação, o retorno das direções das associações para agendamento das entrevistas foi rápido. O primeiro contato foi no dia 08 de outubro de 2019. No primeiro contato, ainda por telefone, foi apresentado o tema da pesquisa que visa entender os elementos de governança corporativa nessas associações bem como esses elementos promovem um compartilhamento do conhecimento, os diretores indicaram membros da equipe de gestão, que é composta pela direção e vice direção, e um membro da equipe administrativa para responder a pesquisa.

As entrevistas foram feitas com o uso de um roteiro semiestruturado. A primeira entrevista foi com a vice-diretora da $1^{a}$ associação no período da manhã do dia 20/10/2019, a segunda no dia 23/10/2019 na $2^{\text {a }}$ associação e a terceira no dia 25/10/2019 com a $3^{\text {a }}$ associação.

Posteriormente foi realizada a observação direta e a pesquisa documental em cada uma das associações. 


\section{Análise e discussão dos resultados}

A Governança Corporativa é um dos pilares da visão em sustentabilidade. Uma organização com boas práticas de Governança Corporativa é responsável e transparente para com seus associados e também com outras partes interessadas, como os seus colaboradores, fornecedores, clientes, governo, e a sociedade em geral. A Governança Corporativa colabora para o crescimento sustentável da organização a longo prazo.

As boas práticas de Governança Corporativa transformam os princípios em recomendações objetivas, fazendo com que seja alinhado o interesse com a finalidade de preservar e potencializar o valor da empresa, possibilitando seu acesso a recursos e colaborando para a sua longevidade. Como visto anteriormente, a origem das boas práticas de Governança Corporativa está composta por quatro princípios básicos: transparência, equidade, prestação de contas e responsabilidade corporativa. Os resultados apresentados a seguir demonstram o nível de alinhamento das associações estudadas de acordo com os elementos definidos como pilares e princípios básicos da Governança.

As três instituições foram analisadas e estudadas tomando como base seus documentos públicos assim como suas demonstrações contábeis; contudo as mesmas solicitaram sigilo em seus nomes, por esse motivo a referida pesquisa não fará menção aos seus nomes.

$\mathrm{Na}$ sequência, são apresentadas e analisadas as categorias oriundas das questões utilizadas nas entrevistas com as respectivas entidades estudadas nesse estudo.

Quadro 2 - Benefícios oferecidos pela GC

Categoria 1: Benefícios oferecidos pela GC

Definição: A adoção das boas práticas de GC agrega maior valor na imagem das entidades, proporciona melhor transparência na gestão, traz segurança para os agentes e também colabora no tratamento isonômico, além de contribuir para o desempenho sustentável das entidades (Elaborado pelos autores, 2020).

Entrevistado 1: Transparência, é.... gera credibilidade com nossos parceiros, bastante credibilidade. Acho que o maior benefício, pra mim, enquanto Gestora Financeira, é a confiabilidade.

Entrevistado 2: N/D.

Entrevistado 3: Os benefícios que vejo na Governança Corporativa é que ajuda na descentralização na tomada de decisões e na transparência dos gastos da instituição. Fonte: Elaborado pelos autores (2020)

Ao verificar as respostas dos entrevistados 1 e 3, é possível inferir que eles conseguem visualizar como a Governança Corporativa proporciona benefícios à associação. Já com relação ao entrevistado 2, embora não tenha apresentado uma resposta conclusiva para tal 
questionamento, durante a entrevista foi possível identificar que ele conhece e compreende os benefícios que a Governança Corporativa proporciona.

Quadro 3 - Estrutura do conselho de administração e fiscal e a frequência das reuniões

\begin{tabular}{|c|c|}
\hline \multicolumn{2}{|c|}{$\begin{array}{l}\text { Definição: O Conselho de Administração (CA) é o órgão colegiado responsável pelo processo de decisão de } \\
\text { uma empresa em relação ao seu direcionamento estratégico, já o Conselho Fiscal (CF) ele representa um meio } \\
\text { de fiscalização independente dos administradores para o reporte aos sócios, inserido por decisão da assembleia } \\
\text { geral, cujo objetivo é preservar o valor da empresa. A frequência refere-se à periodicidade de que esses órgãos } \\
\text { se reúnem, juntos ou individuais, para debatem assuntos referentes a entidade (Elaborado pelos autores, 2020). }\end{array}$} \\
\hline $\begin{array}{l}\text { Subcategoria 1: Estrutura do conselho de } \\
\text { administração }\end{array}$ & $\begin{array}{l}\text { Entrevistado 1: Elas foram eleitas também, conforme } \\
\text { prevê o estatuto. São, a, Presidente e Vice-Presidente. } \\
\text { [...] são mandatos de } 4 \text { anos, o mandado delas se } \\
\text { encerra ano que vem [...]elas também foram eleitas } \\
\text { através de votação pelos associados. } \\
\text { Entrevistado 2: o Conselho de Administração. [...] ele } \\
\text { é constituído também por } 3 \text { integrantes [...] é } \\
\text { Presidente, Diretor Financeiro, e Diretora Pedagógica. } \\
\text { Entrevistado 3: A diretoria (Conselho administrativo) } \\
\text { é eleita em assembleia geral, com mandado de quatro } \\
\text { anos. }\end{array}$ \\
\hline Subcategoria 2: Estrutura do conselho fiscal & $\begin{array}{l}\text { Entrevistado 1: O Conselho Fiscal ele foi estruturado } \\
\text { a partir de eleição, né. É ... então, os membros foram } \\
\text { eleitos pelos associados, isso conforme tá previsto no } \\
\text { nosso estatuto. } \\
\text { Entrevistado 2: a Associação, ela estabeleceu o } \\
\text { estatuto dela em 2007, dentro do estatuto de } \\
\text { constituição e de formalização da associação, já estão } \\
\text { previstos os conselhos fiscais, ou conselhos de } \\
\text { administração. [...] composto por } 3 \text { integrantes, que } \\
\text { validam as operações, as movimentações do ano } \\
\text { anterior. } \\
\text { Entrevistado 3: [...]o Conselho fiscal é eleito nesta } \\
\text { mesma assembleia que o Conselho Administrativo. }\end{array}$ \\
\hline Subcategoria 3: Frequência de reuniões & $\begin{array}{l}\text { Entrevistado 1: Então, hoje são previstas } 2 \text { reuniões } \\
\text { anuais. } \\
\text { Entrevistado 2: O Conselho Fiscal ele se reúne uma } \\
\text { vez por ano, no encerramento do exercício, ali, } \\
\text { loguinho em Janeiro ou Fevereiro, é feito uma reunião } \\
\text { com o conselho. [...] Já o Conselho de Administração, } \\
\text { que nós aqui chamamos Conselho Executivo, a gente } \\
\text { se reúne praticamente toda semana. } \\
\text { Entrevistado 3: As reuniões com a diretoria são em } \\
\text { média uma vez por semana. }\end{array}$ \\
\hline
\end{tabular}


Com base nas respostas dos entrevistados nas subcategorias 1 e 2 foi possível identificar que todas possuem estruturados em sua respectiva Associação o Conselho Administrativo e Conselho Fiscal, que são um dos pilares da Governança Corporativa.

Quando se adentra a subcategoria 3, foi possível identificar que todos os entrevistados, em suas respectivas Associações, realizam periodicamente as reuniões de seus Conselhos.

\section{Quadro 4 - Apresentação dos Demonstrativos Contábeis}

Categoria 3: Apresentação dos Demonstrativos Contábeis.

Definição: As comunicações institucionais são aquelas que a instituição tem para com os seus usuários (internos e externos) referente a sua atual situação e também do seu planejamento para o futuro. E tal comunicação se dá por meio, dos Demonstrativos Contábeis, que podem ser disponibilizados para a sociedade e também serem apresentados aos seus associados (ELABORADO PELOS AUTORES, 2020).

Entrevistado 1: A gente publica os demonstrativos no site da Associação, os demonstrativos contábeis, alguns deles e o relatório, uma parte do relatório de auditoria.

Entrevistado 2: Para com a sociedade a gente tem uma forma de comprovar essa transparência registando todos os nossos balanços, todas as nossas atas, todo nosso conselho fiscal e registrando nossas atas em cartório. [...] a gente procura bimestralmente aqui com os nossos internos que são os nossos professores, os nossos funcionários fazer essa explanação e dar andamento.

Entrevistado 3: As atividades tanto para divulgar/convidar, tanto após atividades são divulgados nas redes sociais. No final do ano é feito um relatório anual de todas as atividades. Não tínhamos o costume de colocar balanço na internet. Apresentação apenas quando um associado solicitava.

Fonte: Elaborado pelos autores (2020)

Ao verificar as respostas dos entrevistados, foi possível observar que somente as instituições dos entrevistados 1 e 2 apresentam seus Demonstrativos Contábeis para a sociedade, seja por meio de seu web site, seja registando em cartórios, além disso, todas as associações apresentam periodicamente essas informações para seus colaboradores e associados. 
Quadro 5 - Estrutura de organograma da entidade e os gestores responsáveis pela tomada de decisões

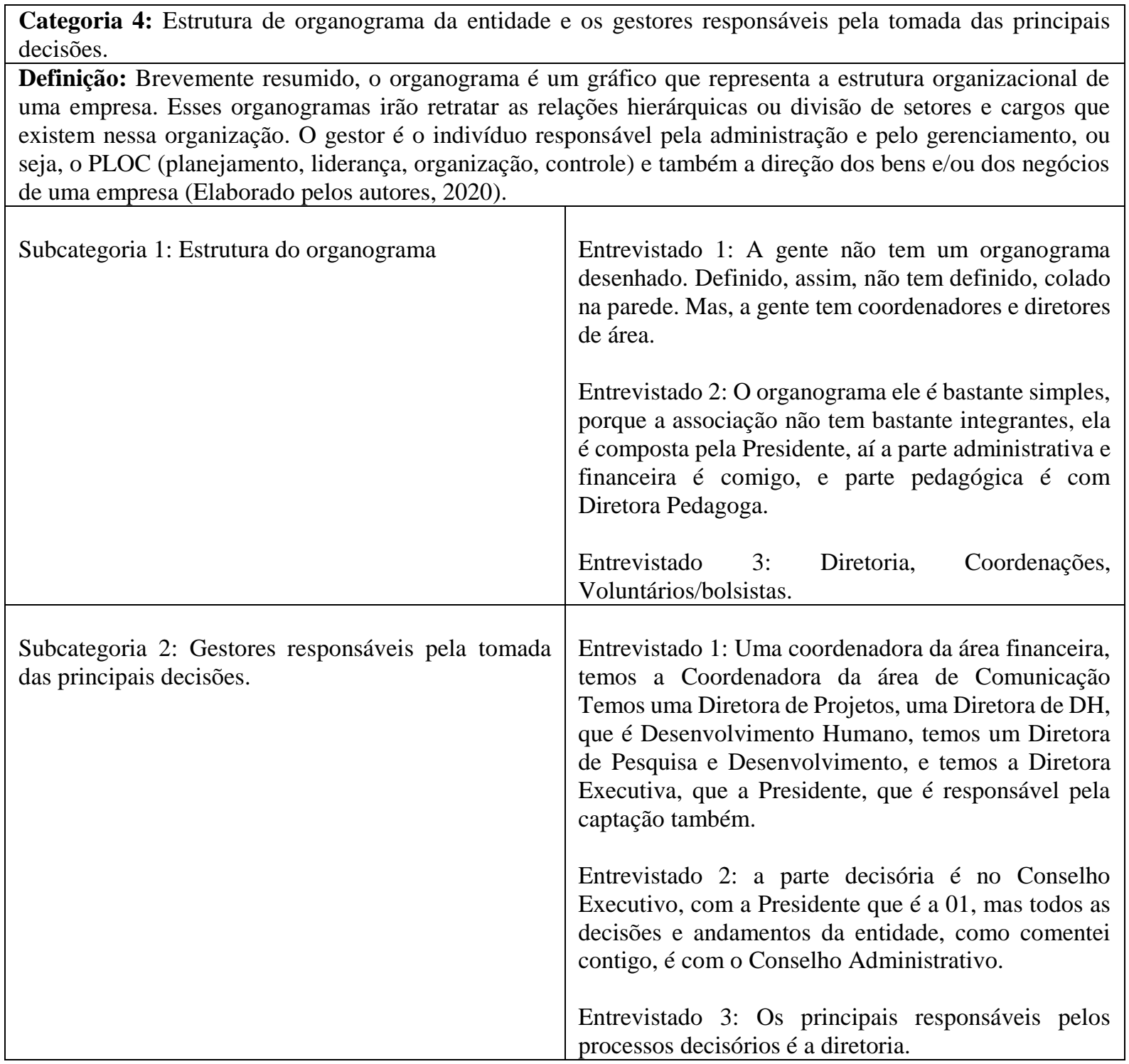

Fonte: Elaborado pelos autores (2020)

Com base nas respostas apresentadas pelos entrevistados foi possível identificar que todos, em suas respectivas associações, possuem um organograma de sua estrutura organizacional na forma funcional, ou seja, estrutura é montada pela função de cada departamento.

Na sequência, observa-se que os gestores responsáveis pela tomada das principais decisões compõem o corpo diretivo das respectivas associações pesquisadas, ou seja, Presidentes e Diretores/Coordenadores. 
Quadro 6 - Decisões com base em Demonstrações Contábeis

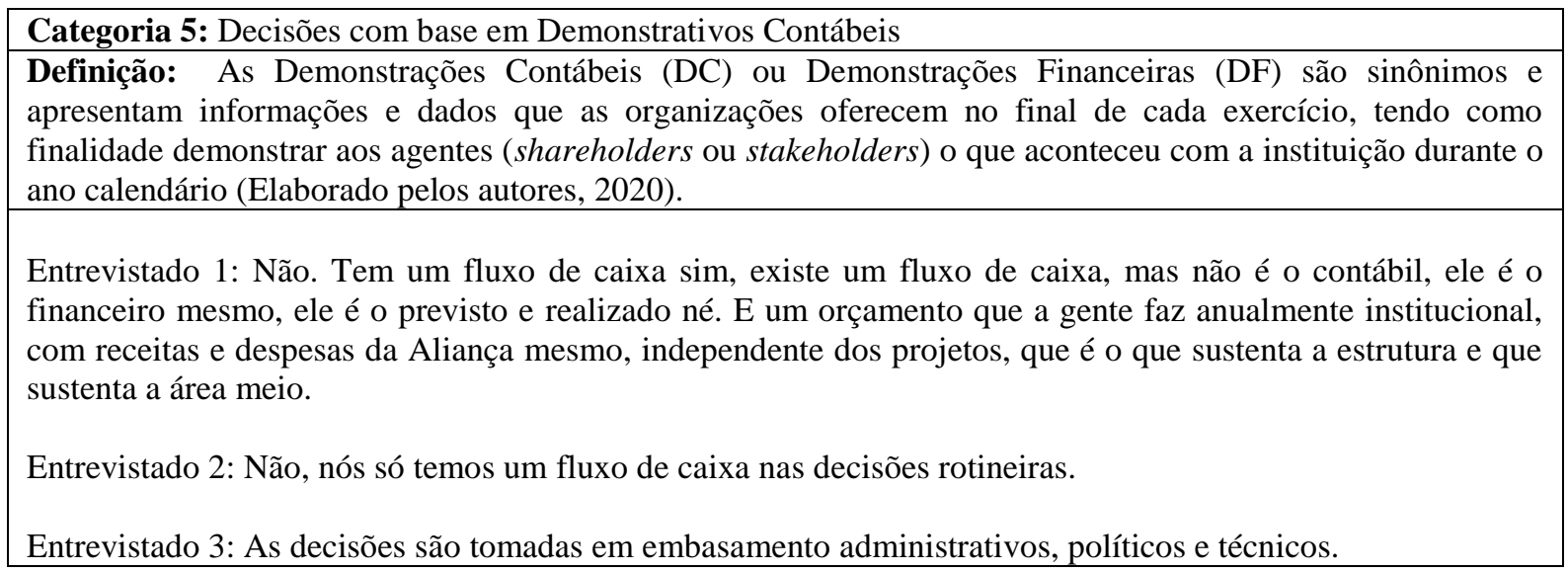
Fonte: Elaborado pelos autores (2020)

Ao verificar as respostas dos entrevistados, é possível identificar que nenhum dos entrevistados utilizam os Demonstrativos Contábeis para tomar decisões em sua Associação, entretanto, os entrevistados 1 e 3 tomam suas decisões com base em documentos internos, elaborados pela própria entidade.

Com base nas respostas obtidas por meio da entrevista e do questionário aplicado às instituições, foi possível inferir que as associações pesquisadas compreendem a importância dos pilares, dos princípios e das boas práticas de Governança Corporativa.

Contudo, para atender a todos os requisitos da Governança, fazem-se necessárias adaptações em suas atividades, para implementar e estruturar todos os pilares, mesmo que não haja obrigatoriedade legal, o que agregará maior valor a sua imagem, transparência na gestão, e segurança a todos os agentes organizacionais (shareholders e stakeholders).

Antes de apresentar o último, mas mais importante questionamento aos entrevistados, que foi sobre como eles visualizam o modo como o compartilhamento do conhecimento em suas instituições são potencializados por meio, da aplicação das boas práticas de Governança Corporativa, foi lhes apresentado o conceito de conhecimento, gestão do conhecimento e compartilhamento do conhecimento e também com o auxílio de situações exemplificado a prática e relação desses conceitos. 
Quadro 7 - Os pilares de Governança Corporativa e sua relação com o compartilhamento do conhecimento \begin{tabular}{l} 
Categoria 6: Os pilares de Governança Corporativa e sua relação com o compartilhamento do conhecimento \\
\hline Definição: Os pilares de GC são compostos por vários elementos em uma instituição e esses pilares quando \\
alinhados com o compartilhamento do conhecimento poderão potencializar os resultados organizacionais. O \\
compartilhamento de conhecimento é uma ação que beneficia a organização em vários sentidos, um deles, é a \\
melhora em seu processo organizacional, esse compartilhamento do conhecimento. (ELABORADO PELOS \\
AUTORES, 2020).
\end{tabular}

Entrevistado 1: Como aqui na instituição tudo é muito prático, então nem sabíamos que desenvolvendo esses pilares da GC iriamos melhorar nosso compartilhamento do conhecimento, e nem sabíamos que compartilhamento do conhecimento seria tudo isso. Mas analisando como calma e com detalhes, sim, esses pilares iriam com certeza ajudar no compartilhamento do conhecimento.

Entrevistado 2: É verdade viu... Eu nunca tinha parado para pensar sobre isso, mas desenvolvemos a maioria desses pilares de GC que o IBGC [é esse o nome, né?] nos indica e tenho certeza que isso está contribuindo com o compartilhamento do conhecimento. Um ação bem legal que fazemos aqui e que trata sobre o compartilhamento do conhecimento é a divulgação das nossas informações contábeis-financeira, hoje nós registramos em cartório, mas também discutimos os resultados com nossos colaboradores e isso também nos ajuda a ter ideias e aumentar ainda mais o engajamento internos sobre nosso causa com os nossos pares.

Entrevistado 3: Olha eu vejo que os pilares de GC vem de encontro com o compartilhamento do conhecimento, sabia que nunca havia pensado nisso, nem que esse compartilhamento poderia ser melhor tratado e ajustado. Falando nisso em nossas reuniões no conselho fiscal que também chamamos de executivo, compartilhamos vários assuntos de interesse da instituição e, depois que você [entrevistador] me explicou o que é o compartilhamento do conhecimento, temos certeza que fazemos isso, pois, a troca de ideias é constante e isso vem potencializando os resultados de nossa instituição.

Fonte: Elaborado pelos autores (2020)

Foi possível visualizar no conteúdo do quadro 5, que todos os entrevistados são enfáticos a respeito de como as boas práticas de GC indicadas pelo IBGC podem potencializar e alinhamento o processo de compartilhamento do conhecimento em suas instituições, sendo até apresentado pelos mesmos, exemplos reais dessas práticas.

É interessante notar, contudo, que os entrevistados indicam que antes da colocação do entrevistador sobre os conceitos apresentados, não haviam refletido sistematicamente sobre as vantagens da aplicação da Governança Corporativa e de seus elementos (pilares e princípios) em suas associações. Podemos inferir que a ausência de informação e de reflexão sobre as teorias da gestão, e neste caso sobre a Governança Corporativa, no âmbito das organizações da sociedade civil, pode reduzir a capacidade de aplicação e/ou utilização dessas teorias por parte dos gestores.

Depreende-se que, embora as organizações do Terceiro Setor tenham ganhado amplitude e maior profissionalização ao longo dos últimos anos, ainda assim carecem de ferramentas e desenvolvimento de cultura organizacional que privilegie o acesso à informação e o compartilhamento de conhecimento entre os gestores. 


\section{Considerações finais}

O presente estudo buscou evidenciar a aplicação dos pilares de Governança Corporativa em entidades do Terceiro Setor, notadamente as associações assistenciais estudadas, e se estas estão aptas para atender tais pilares, de modo a promover o compartilhamento de conhecimento.

Os resultados obtidos na realização das entrevistas demonstram que os gestores das associações estudadas compreendem a importância das boas práticas de Governança Corporativa, além de seguir alguns de seus princípios e atender parcialmente aos pilares, de forma intrínseca ou não, ou seja, têm ciência da aplicação, ou aplicam-nos mesmo sem os conhecer, respectivamente. E atendem, parcialmente, às exigências expostas pela Governança Corporativa.

Além desta constatação, foi possível evidenciar a contribuição do referencial teórico, que de forma abrangente relatou os benefícios da aplicação dos pilares e dos princípios da Governança Corporativa no Terceiro Setor, deixando claro que em caso de as associações estudadas, aderirem às práticas de Governança Corporativa, passarão a ter uma visão mais positiva por parte do mercado, e isso poderia contribuir com o processo de arrecadação de recursos para a manutenção de suas atividades.

Tão relevante quanto atender aos pilares de GC é que os entrevistados visualizam como muito importante a contribuição que esses pilares fornecem ao processo de compartilhamento do conhecimento, na pergunta a respeito do elo entre o compartilhamento do conhecimento e esses pilares o entrevistado 3 relatou que o conselho de administração realiza frequentes reuniões (até semanais) com os associados, seja para comunicar uma informação oficial da associação, como também para trocar informações sobre a gestão da instituição e assim, fortalecer a relação entre esses dois agentes, esse é um dos vários exemplos citados pelos entrevistados que vão de encontro com o conceito e aplicação do compartilhamento do conhecimento.

Assim, pode-se chegar à conclusão que a Governança Corporativa e seus pilares, quando aplicada de forma adequada, pode sim, contribuir para o desenvolvimento do processo de compartilhamento do conhecimento em entidades do Terceiro Setor, visto que, conforme mencionado no decorrer desta pesquisa, isso trará às entidades uma visão mais positiva em relação ao mercado e aos demais membros de sua rede social. 
Como ressalva, entende-se que um limitador à capacidade contributiva da Governança Corporativa ao compartilhamento de conhecimento está relacionado às limitações gerenciais comuns ao Terceiro Setor brasileiro.

\section{Referências}

ANDRADE, A.; ROSSETTI, J. P. Governança corporativa: fundamentos, desenvolvimento e tendências. 3. ed. atual. ampl. São Paulo: Atlas, 2006.

BARBIERI, C. B. Terceiro setor: desafios e perspectivas constitucionais. Curitiba: Juruá, 2008.

BARDIN, L. Análise de conteúdo. Lisboa: Edições 70, 2011, p. 1-49.

BENEDICTO, S. C.; GUIMARÃES JÚNIOR, E. S.; PEREIRA, J. R.; ANDRADE, G. H. N. Governança corporativa: uma análise da aplicabilidade dos seus conceitos na administração pública. Organizações Rurais \& Agroindustriais, Lavras, v. 15, n. 2, p. 286-300, 2013.

DAVENPORT, T. H.; PRUSAK, L. Ecologia da informação. São Paulo: Futura, 1998.

FLYVBERJERG, B. Five misunderstandings about case-study research. Qualitative Inquiry, [s.l.], v. 12, n. 2, p. 219-2045, 2006.

HOFFMANN, W. A. M. Gestão do conhecimento: desafios de aprender. São Carlos: Compacta, 2009.

HOFFMANN, W. A. M. Gestão do conhecimento e da informação em organizações baseados em inteligência competitiva. Ciência da Informação, Brasília, v. 45, n. 3, 22 fev. 2018. Disponível em: http://revista.ibict.br/ciinf/article/download/4045/3564/. Acesso em 22 out. 2019.

IBGC. Código das melhores práticas de governança corporativa. 5. ed. [s. l.]: IBGC, 2015. Disponível em: https://conhecimento.ibgc.org.br/Paginas/Publicacao.aspx?PubId=21138. Acesso em: $31 \mathrm{mar}$. 2020.

MARTINS, O. S.; VENTURA JR. R. Influência da governança corporativa na mitigação de relatórios financeiros fraudulentos. Revista Brasileira de Gestão de Negócios, São Paulo, v. 22, n. 1, p 65-84, 2020. Disponível em: http://rbgn.fecab.br/RBGN/article/view/4039. Acesso em: 20 jul. 2020.

MINISTÉRIO DA JUSTIÇA (Brasil). Consulta a entidades qualificadas: conheça as entidades qualificadas como Organização da Sociedade Civil de Interesse Público (OSCIP) em sua cidade. 2020. Disponível em:

http://portal.mj.gov.br/SistemaOscip/resultadoconsulta.asp. Acesso em: 11 set. 2020.

NONAKA, I.; TAKEUCH, H. Gestão do conhecimento. Porto Alegre: Bookman, 2008. 
SILVA, A. L. P. Governança institucional: um estudo do papel e da operação dos conselhos das organizações da sociedade civil no contexto brasileiro. São Paulo: Atlas, 2016.

TONET, H. C.; PAZ, M. G. T. Um modelo para o compartilhamento de conhecimento no trabalho. Ver. Adm. Contemp., Curitiba, v. 10, n. 2, p. 75-94, jun. 2006. Disponível em: http://www.scielo.br/scielo.php?script=sci_arttext\&pid=S141565552006000200005\&lng=en\&nrm=iso. Acesso em: 31 mar. 2020.

VALENTIM, M. L. P. Ambientes e fluxos de informação em contextos empresariais: o caso do setor cárnico de Salamanca/Espanha. Brazilian Journal of Information Science, Marília, v. 7, n. especial, p. 299-323, $1^{\circ}$. sem. 2013. Disponível em:

https://www2.marilia.unesp.br/index.php/bjis/article/view/3130. Acesso em: 08 out. 2019.

YIN, R. K. Case study research: design and methods. 5. ed. Thousand Oaks: Sage Publications, 2015.

YIN, R.K. Qualitative research from start to finish. New York: The Guilford, 2011.

SZABO, V.; COSTA, B. K.; RIBEIRO, H. C. M. Stakeholders e sustentabilidade: produção científica internacional entre 1998 e 2011 . REBRAE: Revista Brasileira de Estratégia, Curitiba, v. 7, n. 2, p. 174-190, maio/ago. 2014. Disponível em: http://wwww.pucpr.br/reol/pb/index.php/rebrae?dd99-issue\&dd0=620. Acesso em 15 jul. 2020. 